\title{
RELIGIOGRAFIA dAS PESqUiSAS SOBRE A SECULARIZAÇÃo NAS TESES E DissertaÇões dos Programas de Pós-GRADUAÇÃo EM CiÊNCIAS DA RELIGIÃo NO BRASIL
}

\author{
RELIGIOGRAPHY OF RESEARCH ON SECULARIZATION IN THESIS AND \\ Dissertations of Postgraduate Programs in RELIGIOUS StUdies IN \\ BRAZIL
}

Maurílio Ribeiro da Silva*

\begin{abstract}
RESUMO
A secularização da sociedade é um processo histórico e social de fundamental importância na formação das sociedades modernas e nos processos subjetivos de autonomia, racionalização e emancipação do indivíduo e das instituições político/jurídicas. Ela não extinguiu a religião, entretanto, a religião e seus símbolos sagrados perderam a capacidade de ordenamento e legitimação da realidade. A secularização além de definir fenômenos religiosos, passou a definir fenômenos sociais, culturais, econômicos, históricos e psicológicos. Essa polissemização do termo gerou inúmeras pesquisas e discussões científicas. Essa comunicação apresenta o estado da arte das pesquisas sobre secularização no Brasil obtido através da pesquisa religiográfica da produção discente de teses e dissertações nos PPGCR nacionais sobre a temática da secularização. São apresentados os resultados obtidos na elaboração da dissertação Secularização à Brasileira: uma investigação sobre o estado da arte da discussão sobre a secularização a partir das teses e dissertações dos programas de pós-graduação em Ciências da Religião no Brasil de 1978 a 2012.
\end{abstract}

Palavras-chave: Religiografia. Secularização. Programas de Pós-Graduação em Ciências da Religião.

\begin{abstract}
The secularization of society is a historical and social process of fundamental importance in the formation of modern societies and in the subjective processes of autonomy, rationalization and emancipation of the individual and of political/legal institutions. It did not extinguish religion, however, religion and its sacred symbols lost the ability to order and legitimize reality. Secularization, in addition to defining religious phenomena, began to define social, cultural, economic, historical and psychological phenomena. This polysemization of the term generated numerous research and scientific discussions. This communication presents the state of the art of research on secularization in Brazil obtained through the religiographic research of student production of theses and dissertations in the national PPGCR on the theme of secularization. The results obtained in the preparation of the dissertation Secularization to Brazilian: a state of the art investigation of the discussion about secularization based on theses and dissertations of postgraduate programs in Religious Studies in Brazil from 1978 to 2012.
\end{abstract}

Keywords: Religiography. Secularization. Graduate Programs in Religious Studies.

\footnotetext{
* Mestre em Ciências da Religião - PUC Minas. Doutorado em andamento em Ciências da Religião na PUC Minas. Pós- graduado em Sociologia pela Universidade Gama Filho de São Paulo, em Filosofia Contemporânea pela PUC Minas e em Teologia Sistemática pela Faculdade Batista de Minas Gerais. Graduado em Teologia pelo Centro Universitário Metodista Izabela Hendrix. Brasil. ORCID: 00oo-00023673-5215. E-mail: sgmaurilio@gmail.com.
} 


\section{INTRODUÇÃO}

A secularização da sociedade é um processo histórico decisivo na formação das sociedades modernas ocidentais, tendo contribuído para os processos de autonomia, racionalização e emancipação do sujeito, das instituições político/jurídicas e das atividades artísticas e culturais em geral. Para Peter Berger (2012) a secularização se configura objetivamente num processo social em que a religião e seus símbolos perdem a credibilidade e a capacidade de legitimação da realidade. O processo ocorre em face de alterações na concepção de mundo do indivíduo, uma vez que a religião perde o seu caráter determinante e evidente sobre a consciência humana.

O termo secularização assumiu características polissêmicas, sendo utilizado na definição de uma série de fenômenos sociais, culturais, econômicos e religiosos. O processo de secularização como fenômeno histórico e fenômeno subjetivo da consciência humana, se tornou objeto de pesquisa em diversas áreas do saber. Essa comunicação, entretanto, se limita à análise das teses e dissertações sobre o tema da secularização produzidas no âmbito das Ciências da Religião no Brasil.

Os primeiros programas de pós-graduação em Ciências da Religião (PPGCR) foram instituídos no Brasil no final dos anos 70, porém, a primeira pesquisa discente sobre a secularização surgiu apenas em 1999. A investigação da secularização na produção discente dos PPGCR foi centrada nos temas: biodança, teologia da secularização, análise histórica, filosofia da religião, sociologia da religião, filosofia do direito, análise estatística e campo axiológico das relações de mercado (SILVA, 2016).

Diante desse horizonte abrangente e polissêmico, buscando estabelecer a possibilidade de uma secularização à brasileira é que foi produzida a dissertação, a partir do método religiográfico, da qual destacamos essa comunicação (SILVA, 2016). As teses e dissertações dos PPGCR foram escolhidas a partir da presença do termo secularização nas palavras chaves. Após coletadas segundo o critério escolhido, foram identificadas o9 pesquisas (07 dissertações e duas teses) ${ }^{1}$.

\footnotetext{
1 1) 1999 (UMESP): Desencantamento e reencantamento do mundo sobre a atualidade da teologia da secularização - Dissertação (SILVA, 1999); 2) 1999 (UFJF): Biodança: religiosidade ou secularização radical - Dissertação (LEITE, 1999); 3) 2000 (UMESP): Axiologia, religião e secularização nos negócios: uma análise da competitividade em pequenas e médias empresas brasileiras - Tese (BRANDÃO, 2000); 4) 2003 (UMESP): A secularização do ocidente: o declínio e o reavivamento da religião na modernidade e seus reflexos no Brasil - Dissertação (ALMEIDA, 2003); 5) 2008 (UFJF): Os 'sem religião' no Brasil: um estudo sócio-antropológico sobre suas interpretações e consequências - Tese (MAGALDI, 2008); 6) 2009 (Mackenzie): A teologia da secularização de Harvey Cox e sua busca pela plausibilidade para o cristianismo - Dissertação (PEREIRA, 2009); 7) 2009 (UMESP): O retorno da religião na época da superação da metafísica: religião e secularização no pensamento de G. Vattimo - Dissertação (BALEEIRO, 2009); 8) 2011
} 
A pesquisa religiográfica empreendida teve por objetivo estabelecer as principais tendências teóricas das pesquisas sobre a secularização, bem como estabelecer as seguintes relações de produção acadêmica: 1) produção em relação ao tempo; 2) espaço geográfico; 4) autores mais citados nas pesquisas; 5) autores mais citados por obras; 6) obra mais utilizada nas citações, 7) principais instituições produtoras de pesquisas, 8) tipo de instituição, e 9) confessionalidade das instituições.

\section{LEVANTAMENTO RELIGIOGRÁFICO E RESULTADOS OBTIDOS}

Para elaborar a pesquisa religiográfica das pesquisas sobre a secularização nas teses e dissertações dos PPGCR brasileiros, alguns passos foram seguidos. A pesquisa religiográfica, à semelhança das pesquisas estado da arte, busca obter dados seguros para o estabelecimento de análises e/ou diagnósticos da produção de determinado tema. No caso da pesquisa religiográfica, o tema deve ser relacionado aos estudos da religião. A pesquisa religiográfica seguiu basicamente cinco etapas: 1) pesquisa bibliográfica e escolha das pesquisas sobre a temática da secularização; 2) organização e sistematização dos dados a partir da ordem cronológica; 3) leitura das teses e dissertações selecionadas; 4) organização e sistematizações das pesquisas através de fichamento e cruzamento dos dados; 5) Demonstração qualitativa e quantitativa (estatística) dos dados obtidos através de gráficos, tabelas e colunas.

O primeiro resultado obtido diz respeito às principais tendências teóricas das teses e dissertações sobre o tema da secularização. Duas tendências emergiram das pesquisas: 1) a temática foi analisada nas pesquisas sob a ótica dualista de oposição entre secularização e religião. Essa constatação se dá em oito, dos nove trabalhos analisados, o que demonstra a influência de Peter Berger (influenciado por Max Weber) na conceituação da secularização; 2) as pesquisas foram elaboradas sob o viés da Sociologia, Teologia, Filosofia e História, evidenciando a polarização do interesse investigativo dos estudos da secularização nas Ciências Humanas e na compreensão.

A segunda questão (tabela 1) sobre a produção acadêmica em relação ao tempo constatou que a primeira pesquisa sobre a secularização foi concluída após vinte e um anos da institucionalização das Ciências da Religião no Brasil, de modo tardio, já que nesse mesmo ano Peter Berger (2001) voltou atrás em suas considerações sobre a secularização,

(PUC MG): A aceitação irônica do sagrado: Gianni Vattimo e a secularização - Dissertação (SILVA, 2011); 9) 2012 (PUC MG): Dialética da secularização: uma perspectiva discursiva entre razão e religião em Jürgem Habermas - Dissertação (ARAÚJO, 2012). 
além do fato de que temas como dessecularização, retorno do sagrado e reencantamento do mundo já estavam em pauta.

Tabela 1: relação ao tempo

\begin{tabular}{|l|c|c|}
\hline Ano & Quantidade & $\%$ \\
\hline 1999 & 2 & 22,2 \\
\hline 2000 & 1 & 11,11 \\
\hline 2003 & 1 & 11,11 \\
\hline 2008 & 1 & 11,11 \\
\hline 2009 & 2 & 22,22 \\
\hline 2011 & 1 & 11,11 \\
\hline 2012 & 1 & 11,11 \\
\hline
\end{tabular}

Fonte: dados da pesquisa

A terceira questão (tabela 2) diz respeito ao espaço geográfico das produções acadêmicas sobre o tema da secularização. As pesquisas ficam restritas aos PPGCR São Paulo com cinco pesquisas (PUC SP; UMESP; Mackenzie) e Minas Gerais com quatro (UFJF; PUC Minas).

Tabela 2: relação espaço geográfico

\begin{tabular}{|l|c|c|}
\hline Estado & Quantidade & $\%$ \\
\hline São Paulo & 5 & 55,56 \\
\hline Minas Gerais & 4 & 44,44 \\
\hline
\end{tabular}

Fonte: dados da pesquisa

A quarta questão (tabela 3) diz respeito aos autores mais citados por número de pesquisas. Peter Berger e Friedrich Nietzsche são os mais citados nas pesquisas. Rubem Alves aparece em terceiro lugar, ao lado de Max Weber. 


\section{Tabela 3: Principais autores}

\begin{tabular}{|l|c|}
\hline \multicolumn{1}{|c|}{ Autores } & Citações \\
\hline Peter Berger & 7 \\
\hline Friedrich Nietzsche & 7 \\
\hline Rubem Alves & 6 \\
\hline Max Weber & 6 \\
\hline José Comblin & 4 \\
\hline Harvey Cox & 2 \\
\hline Gianni Vattimo & 2 \\
\hline Jürgen Habermas & 2 \\
\hline Dietrich Bonhoeffer & 2 \\
\hline Émile Durkheim & 2 \\
\hline
\end{tabular}

Fonte: dados da pesquisa

A quinta questão (tabela 4) analisada apresenta determinado conflito em relação a questão anterior. Em relação aos autores mais citados por obras, Gianni Vattimo é o primeiro colocado com 43 citações (o autor é citado em apenas duas pesquisas) e, Jürgen Habermas o segundo, com 37 citações.

Tabela 4: Autores mais citados por obras

\begin{tabular}{|l|c|}
\hline \multicolumn{1}{|c|}{ Autores } & Citações \\
\hline Gianni Vattimo & 43 \\
\hline Jürgen Habermas & 37 \\
\hline Friedrich Nietzsche & 22 \\
\hline Peter Berger & 16 \\
\hline
\end{tabular}

Fonte: dados da pesquisa

A sexta questão (tabela 5) faz jus a presença maciça de Peter Berger nas pesquisas. A 
obra mais utilizada nas citações das teses e dissertações foi $O$ dossel sagrado, presente em seis das nove pesquisas. Apesar de Berger ter voltado atrás em diversos pontos presentes nessa obra, ela permanece a obra prima da secularização no Brasil. Em seguida vem A gaia ciência, de Nietsche, e Rumor de Anjor de Berger, ambas com 3 citações.

\section{Tabela 5: Obras mais citadas nas referências}

\begin{tabular}{|l|c|}
\hline \multicolumn{1}{|c|}{ Obras } & Qtde \\
\hline O Dossel Sagrado & 6 \\
\hline A Gaia Ciência & 3 \\
\hline Rumor de Anjos & 3 \\
\hline
\end{tabular}

Fonte: dados da pesquisa

A sétima questão (tabela 6) analisou as instituições que mais produziram pesquisas sobre o tema da secularização. A Universidade Metodista do Estado de São Paulo (UMESP), liderou o ranking com 4 pesquisas (1 tese e 3 dissertações); seguida pela Universidade Federal de Juiz de Fora (UFJF), com 2 pesquisas ( 1 tese e 1 dissertação) e a Pontifícia Universidade Católica de Minas Gerais (PUC Minas), também com duas pesquisas (2 dissertações); e por último a Universidade Presbiteriana Mackenzie, com 1 dissertação

\section{Tabela 6: Distribuição da pesquisa em relação as instituições}

\begin{tabular}{|c|c|c|}
\hline Instituição & Quantidade & $\%$ \\
\hline UMESP & 4 & 44,44 \\
\hline UFJF & 2 & 22,22 \\
\hline PUC MINAS & 2 & 22,22 \\
\hline MACKENZIE & 1 & 11,11 \\
\hline
\end{tabular}

Fonte: dados da pesquisa

A oitava questão (tabela 7) analisou a distribuição da pesquisa por tipo de instituição. Há predominância das instituições privadas que respondem por 77,78\% da produção da produção acadêmica sobre o tema da secularização. Já as instituições públicas, respondem por $22,22 \%$. 


\section{Tabela 7: Distribuição da pesquisa por tipo de instituição}

\begin{tabular}{|c|c|c|}
\hline Tipo & Quantidade & $\%$ \\
\hline Privada & 7 & 77,78 \\
\hline Pública & 2 & 22,22 \\
\hline
\end{tabular}

Fonte: dados da pesquisa

A nona questão (tabela 8) trata da confessionalidade das instituições. As instituições de confessionalidade protestante: UMESP e Mackenzie produziram cinco das nove pesquisas ( 1 teses e 4 dissertações), correspondendo a 55,56\% das pesquisas. A PUC Minas, de confessionalidade católica, produziu duas pesquisas (2 dissertações), correspondendo a 22,22\%, e a UFJF (1 tese e 1 dissertação), instituição leiga, também produziu duas pesquisas (1 tese e 1 dissertação) correspondendo também a 22,22\%. Desse modo, foi possível constatar que as instituições confessionais (cristãs) responderam por 77,78\% da produção acadêmica sobre a secularização, e a instituição pública e laica, respondeu por 22,22\%.

\section{Tabela 8: Confessionalidade das instituições}

\begin{tabular}{|c|c|c|}
\hline Tipo & Quantidade & \% \\
\hline Protestante & 5 & 55,56 \\
\hline Católica & 2 & 22,22 \\
\hline Laica & 2 & 22,22 \\
\hline
\end{tabular}

Fonte: dados da pesquisa

\section{CONSIDERAÇÕES FINAIS}

Uma questão evidenciada através da pesquisa é que a investigação da secularização permaneceu restrita à esfera das Ciências Humanas. Esse diagnóstico possibilita a abertura do tema à análise investigativa de outras áreas do conhecimento. Concluímos também que as discussões sobre o tema da secularização são relativamente recentes, e que ficaram restritas geograficamente ao eixo Minas/São Paulo. Outra constatação é que as pesquisas foram construídas à partir de referenciais teóricos estrangeiros, não havendo espaço amplo e diálogo com os autores brasileiros, à exceção de Rubem Alves. De igual modo, nenhuma obra nacional foi citada de modo relevante. Em relação ao problema principal dessa 
pesquisa, baseado nos dados obtidos, afirmamos que há sim, uma secularização à brasileira, ainda que pouco explorada e compreendida, elaborada a partir de um referencial teórico importado, arraigado e enraizado em temáticas e em autores estrangeiros. O rigor na pesquisa científica, aliado ao ateísmo metodológico e a neutralidade axiológica em pesquisas produzidas nos PPGCR, especificamente nos Programas confessionais, é uma prova irrefutável de que a secularização está presente no Brasil, e em pleno vigor sob os auspícios da privatização e polarização religiosa.

\section{REFERÊNCIAS}

ALMEIDA, Marcos Renato Holtz. A secularização do ocidente: o declínio e o reavivamento da religião na modernidade e seus reflexos no Brasil. 2003. 122 f. Dissertação (Mestrado) - Universidade Metodista de São Paulo, Programa de PósGraduação em Ciências da Religião, São Bernardo do Campo, 2003.

ARAÚJO, Paulo Sérgio. Dialética da secularização: uma perspectiva discursiva entre razão e religião em Jürgem Habermas. 2012. 147 f. Dissertação (Mestrado) - Pontifícia Universidade Católica de Minas Gerais, Programa de Pós-Graduação em Ciências da Religião, Belo Horizonte, 2012. Disponível em:

<http://www.biblioteca.pucminas.br/teses/CiencReligiao_AraujoPS_1.pdf>.Acesso em 10 set. 2014 .

BALEEIRO, Cléber Araújo souto. O retorno da religião na época da superação da metafísica: religião e secularização no pensamento de G. Vattimo. 2009. $119 \mathrm{f}$. Dissertação (Mestrado) - Universidade Metodista de São Paulo, Programa de PósGraduação em Ciências da Religião, São Bernardo do Campo, 2009. Disponível em: $<$ http://ibict.metodista.br/tedeSimplificado/tde_busca/arquivo.php?codArquivo=2011 $>$. Acesso em 10 set. 2014.

BERGER, Peter L. A dessecularização do mundo: uma visão global. Religião \& Sociedade, Rio de janeiro, v. 21, n. 1, p. 9-23, abr. 2001.

BERGER, Peter L. O dossel sagrado. 8. ed. São Paulo: Paulus, 2012.

BRANDÃO, João Batista. Axiologia, religião e secularização nos negócios: uma análise da competitividade em pequenas e médias empresas brasileiras. 2000. $243 \mathrm{f}$. Tese (Doutorado) - Universidade Metodista de São Paulo, Programa de Pós-Graduação em Ciências da Religião, São Bernardo do Campo, 2000.

LEITE, Alexandra Aparecida. Biodança: religiosidade ou secularização radical. 1999. 205 f. Dissertação (Mestrado) - Universidade Federal de Juiz de Fora, Programa de PósGraduação em Ciências da Religião, Juiz de Fora, 1999. Disponível em: < http://www.ufjf.br/ppcir/curso/defendidas/dissertacoes/>. Acesso em 10 set. 2014.

MAGALDI, Juliana Alves. Os ‘sem religião’ no Brasil: um estudo sócio-antropológico sobre suas interpretações e consequências. 2008. Tese (Doutorado) - Universidade 
Federal de Juiz de Fora, Programa de Pós-Graduação em Ciências da Religião, Juiz de Fora, MG, 2008.

PEREIRA, Olivar Alves. A teologia da secularização de Harvey Cox e sua busca pela plausibilidade para o cristianismo. 2009. $161 \mathrm{f}$. Dissertação (Mestrado) Universidade Presbiteriana Mackenzie, Programa de Pós-Graduação em Ciências da Religião, São Bernardo do Campo, 2009. Disponível em $<$ http://www.dominiopublico.gov.br/pesquisa/DetalheObraForm.do?select_action=\&co_ obra $=181243>$. Acesso em 10 set. 2014 .

SILVA, Marcos Paulo Nogueira da. A aceitação irônica do sagrado: Gianni Vattimo e a secularização. 2011. 100 f. Dissertação (Mestrado) - Pontifícia Universidade Católica de Minas Gerais, Programa de Pós-Graduação em Ciências da Religião, Belo Horizonte, 2011. Disponível em:

<http://www.pucminas.br/imagedb/documento/DOC_DSC_NOME_ARQUI20110705151 128.pdf $>$. Acesso em 10 set. 2014.

SILVA, Oseias Barbosa. Desencantamento e reencantamento do mundo sobre a atualidade da teologia da secularização. 1999. 111 f. Dissertação (Mestrado) Universidade Metodista de São Paulo, Programa de Pós-Graduação em Ciências da Religião, São Bernardo do Campo, 1999.

SILVA, Maurílio Ribeiro. Secularização à brasileira: Uma investigação sobre o estado da arte da discussão sobre a secularização a partir das teses e dissertações dos programas de pós-graduação em Ciências da Religião no Brasil de 1978 a 2012. Dissertação (Mestrado em Ciências da Religião), PUC Minas, Belo Horizonte, 2016. 